Arch. Vet. Scienc. 3(1):9-19, 1998

Printed in Brazil

\title{
ASPECTOS FISIOLÓGICOS E PATOLÓGICOS DO PUERPÉRIO EM BOVINOS
}

\section{LUIZ ERNANDES KOZICKI}

Departamento de Medicina Veterinária, Setor de Ciências Agrárias, Universidade Federal do Paraná, Caixa

Postal 2959 - CEP 80001-970 - Rua Jaime Balão, 575 -Curitiba - Paraná - Brasil- Fax: (041) 252-3689

\begin{abstract}
A review on the physiological and pathological aspects of the puerperium in bovines is being carried out. The following topics were discussed: general aspects of the puerperium; PGF2 $\alpha$ and uterine involution; ovarian activity; ovarian folicles; ovulation; LH and FSH; GnRH; progestagens; bovine anestrus; sources of energy and anestrus; concomitant affections during the puerperium period.
\end{abstract}

Key Words: Bovine, puerperium, physiology, pathology, endocrinology.

RESUMO - Foi levado a efeito uma revisão sobre os aspectos fisiológicos e patológicos do puerpério em bovinos. Os seguintes tópicos foram discutidos: aspectos gerais do puerpério; PGF2 $\alpha$ e involução uterina; a atividade ovariana; os folículos ovarianos; o LH e o FSH; o GnRH; os progestágenos; o anestro bovino; as fontes de energia e o anestro; as afecções existentes no período do puerpério.

Palavras-Chave: bovinos, puerpério, fisiologia, patologia, endocrinologia.

\section{Fases do Puerpério e Aspectos Gerais}

O período do puerpério é um processo fisiológico e global de modificações que ocorrem na genitália da fêmea, depois do parto, levando o orgão à recuperação das transformações ocorridas durante o período da prenhez, para finalmente atingir volume, tamanho, posição e adquirir novamente a capacidade reprodutiva para futura gestação (GRUNERT e BIRGEL, 1982). OLSON et al., (1986) classificaram o período do puerpério em três estágios distintos: $1^{\circ}$ ) - Periodo puerperal propriamente dito, iniciando-se depois da expulsão fetal e continuando até que a hipófise adquira a capacidade de resposta aos fatores liberadores de gonadotrofinas $(\mathrm{GnRH})$. Esse período está compreendido entre o $7^{\circ}$ e o $14^{\circ}$ dia pós parto (p.p.) ou seja entre a $1^{\mathrm{a}}$ e a $2^{\mathrm{a}}$ semana. $2^{\mathrm{o}}$ ) - Período intermediário, o qual inicia-se com o aumento da sensibilidade hipofisária frente aos estímulos dos GnRH produzidos e liberados do hipotálamo, continuando até que a $1^{\text {a }}$ ovulação torne-se presente. A duração desse período varia, tendo em vista uma série de fatores que influenciam o tempo da ovulação tais como: idade, nível nutricional, parturicão normal ou com complicações, retenção de placenta, infeccção puerperal e estado endócrino. $3^{\circ}$ ) - Periodo pós-ovulatório tendo o começo na ocorrência da $1^{\mathrm{a}}$ ovulação estendendo-se até a involução completa do útero, que se dará em torno da $6^{\mathrm{a}}$ semana em vacas que pariram sem complicações no parto. Nos primeiros 4 dias após o parto, a involução uterina é rápida seguindo uma escala logarítmica (ARTHUR et al., 1989), tornando-se mais lenta a partir do $4^{\circ}$ ao $9^{\circ}$ dia. Há o chamado período refratário do útero, que vai do $4^{\circ}$ ao $7^{\circ} / 8^{\circ}$ dia p.p. (ARTHUR et al., 1989), durante o qual o útero permanece praticamente inerte, não respondendo aos estímulos de hormônios que teriam a capacidade de provocar a contratilidade (GRUNERT e BIRGEL, 1982). A partir do $10^{\circ} \mathrm{e}$ estendendo-se até cerca do $14^{\circ}$ dia p.p. novamente o processo de involução uterina é retomado, quando já existirão alguns folículos ovarianos atuantes (KOZICKI, 1982), em franca produção de estrógenos. Esses hormônios irão favorecer a involução uterina nos seus aspectos globais, completando-se entre a $4^{\mathrm{a}}$ e a $7^{\mathrm{a}}$ semana p.p. (GRUNERT e BIRGEL,1982; KOZICKI, 1982), embora as mudanças após $20 / 25$ dias p.p. sejam pouco perceptíveis. Para que haja o restabelecimento do endométrio, é necessário acontecer o descolamento fisiológico da placenta onde a musculatura uterina promoverá contrações. Nesse processo, as criptas endometriais que eram profundas tornam-se mais aplainadas, as vilosidades coriônicas diminuem de tamanho devido à redução do fluxo sanguineo pelo corte do cordão umbilical, bem como acontecerá a colagenização dos espaços nos placentomas (GRUNERT e BIRGEL, 1982). Durante o puerpério há uma interação entre o útero e os ovários. A involução uterina experimenta complexa série de eventos que incluem contrações miometriais, perda de tecido e epitelialização tecidual (RASBECH, 1950; SCHIRAR e MARTINET, 1982).

Embora a placentação da vaca seja do tipo adeciduado (JAINUDEEN e HAFEZ, 1995), isto é a placenta só é expulsa algumas horas após o nascimento, sabe-se que durante os primeiros 7 a 10 dias p.p., há notável descarga de líquidos chamados 
lóquios. Esses lóquios são formados por substancias remanescentes do fluido fetal, sangue dos vasos rupturados, grânulos de enzimas proteoliticas formados no endométrio durante a gestação, células binucleadas e fagocitárias que já nas primeiras 48 horas p.p., são acionadas e irão iniciar as mudanças necróticas pelas camadas celulares da superfície endometrial (carúnculas) destruídas pela degeneração gordurosa dando origem à secreção serosa na cavidade uterina. Inicialmente, os lóquios tem descarga aproximada de $1500 \mathrm{ml}$. Ainda no $8^{\circ}$ dia há descarga de cerca de $500 \mathrm{ml}$ (GRUNERT e BIRGEL, 1982). Clinicamente, quanto mais viscosa e inodora for a descarga loquial, melhor é o prognóstico reprodutivo. A regeneração do endométrio ocorre imediatamente após o parto naquelas áreas nas quais não houve sérios danos e completa-se na região intercaruncular em torno do $8^{\circ}$ dia pós parto. A completa reepitelialização das carúnculas, originadas em grande parte pelo crescimento celular centrípeto das células que circundam as glândulas uterinas, completa-se a partir do $25^{\circ}$ dia p.p. (ARTHUR et al.,1989).

\section{Prostaglandina $\mathbf{F}_{2 \alpha}$ e Involução Uterina}

Exceto esses aspectos, há que seja considerada a correlação positiva de liberação de prostaglandina $\mathrm{F}_{2 \alpha}\left(\mathrm{PGF}_{2 \alpha}\right)$ e a involução uterina propriamente dita. Durante o puerpério da vaca há maciças liberações de $\mathrm{PGF}_{2 \alpha}$ (KINDAHL et al., 1992; JAINUDEEN e HAFEZ,1995), devido principalmente à elevada incidência de contaminação bacteriana (DeBOIS,1961; FREDRIKSSON et al.,1988). Nos animais que vem a parir sem problemas de retenção de placenta, há inicialmente nos placentomas $\mathrm{PGF}_{2 \alpha}$ em níveis mais elevados do que nas vacas que tiveram a placenta retida (GRUNERT e BIRGEL,1982). O fenômeno endócrino dominante nessa fase do puerpério precoce é a grande quantidade de liberação de $\mathrm{PGF}_{2 \alpha}$. Essa liberação é fortemente influenciada pela contaminação uterina. Existe relação linear entre a duração da liberação de prostaglandina no pós-parto e o tempo de involução uterina. Não há a possibilidade de ocorrer a ovulação pós parto, até que a liberação de $\mathrm{PGF}_{2 \alpha}$ cesse ou que esteja muito próxima dos níveis basais (KINDAHL et al.,1992). Como já foi observado, a $\mathrm{PGF}_{2 \alpha}$ é liberada antes do inicio da parturição e vai acarretar a luteólise do corpo luteo gravídico pré partal, e não permitirá que os ovários iniciem a ciclicidade propriamente dita. Durante cerca de 3 semanas após o parto são encontrados no puerpério das vacas, elevados níveis de $\mathrm{PGF}_{2 \alpha}$, havendo fortes indícios de que ela seja produzida ao nível de endométrio. Em dois diferentes estudos em animais com involução uterina normal foi encontrada negativa correlação entre a duração da liberação de $\mathrm{PGF}_{2 \alpha}$ e a involução uterina (LINDELL et al., 1982; MADEJ et al.,1984) ou somente tendência à correlação negativa, dados concordantes com os de ELEY et al., (1981). Parece existir correlação positiva entre a duração da liberação de prostaglandina e a involução do útero em vacas com descargas uterinas e com variados graus de infecção ou com retenção dos anexos fetais (KINDHAL et al.,1982; LINDELL et al., 1982; WATSON, 1984; BOSU et al., 1984; FREDRIKSSON et al., 1985; MADEJ et al., 1986; BOLINDER et al., 1988). BOSU e PETER (1987) descrevem quadro com maior comprometimento, sugerindo que vacas com infecção uterina podem provocar o aumento de secreção de $\mathrm{PGF}_{2 \alpha}$ e cortisol associado à formação de ovários císticos. Se a duração da liberação de $\mathrm{PGF}_{2 \alpha}$ for muito curta a involução uterina estará prejudicada e se a duração for mais longa o processo involutivo do útero será mais acelerado (KINDHAL et al., 1992).

FREDRIKSSON et al., (1985) pesquisaram dois grupos de vacas, sendo um com animais sem infecção uterina e outro grupo de animais com infecção em seus variados graus de gravidade. $\mathrm{O}$ grupo sem infecção não mostrou correlação entre a liberação de $\mathrm{PGF}_{2 \alpha}$ e a ciclicidade ovariana. Este grupo de animais ovulou mais precocemente $\left(16^{\circ}\right.$ dia em média) quando comparado com o grupo de vacas infectadas $\left(30^{\circ} \mathrm{dia}\right)$, alem de demonstrar elevado percentual de ciclos estrais curtos. Há correlação positiva entre a $1^{\text {a }}$ ovulação (ciclo normal) e a completa involução uterina. Isto significa que animais com mais rápida involução uterina, retornarão também mais rapidamente às atividades ovarianas (KOZICKI, 1982).

Experimentos em vacas sobre a influência da $\mathrm{PGF}_{2 \alpha}$ no p.p. demonstraram que a administração de $P F_{2 \alpha}$ duas vezes ao dia, durante 10 dias seguidos, iniciando-se no $3^{\circ}$ dia pós parturição, acelerou de 7 a 10 dias a involução uterina (LINDELL e KINDAHL, 1983) frente aos animais do grupo controle. Finalmente, os autores concluíram que intenso tratamento de $\mathrm{PGF}_{2 \alpha}$ tem efeito positivo sobre o tonus da musculatura uterina (KINDAHL et al., 1992).

\section{Atividade Ovariana}

Devido ao prolongado período de inibição durante a gestação, pelo continuo feedback negativo da progesterona secretada pelo corpo lúteo (CL) e placenta, a hipófise torna-se temporariamente refratária no pós parto (LAMMING et al., 1979). Entretanto, no puerpério, os ovários freqüentemente contém numerosos folículos que não irão ovular 
Aspectos Fisiológicos e Patológicos do Puerpério em Bovinos

(folículos anovulatórios), os quais tornam-se rapidamente atrésicos e freqüentemente são confundidos como cistos (ARTHUR et al., 1989). Em torno do $30^{\circ}$ dia p.p., a maioria das vacas equilibradamente nutridas devem demonstrar pelo menos um estro. $\mathrm{O}$ intervalo médio do $1^{\circ}$ estro p.p. é de 15 dias em vacas que pariram sem complicações e de 35 dias para animais que tiveram complicações no parto (KOZICKI, 1982). O $1^{\circ}$ ciclo estral, seguido de ovulação é de aproximadamente 17 dias de duração. Muitos dos primeiros estros p.p. com ovulação são silenciosos, e o cio clássico somente será observado em 20 a 30 $\%$ das vacas com corpo lúteo no $30^{\circ}$ dia. Em torno do $30^{\circ}$ dia p.p. o corpo lúteo estará presente em 60 $\%$ das vacas com ovários funcionais; em $20 \%$ haverá cistos do corpo lúteo e $20 \%$ terão folículos císticos. Um corpo lúteo cístico é liso, esférico, massa flutuante que se desenvolve após a ovulação e contém fluido na cavidade central com 0,5 a 1,0 $\mathrm{cm}$ ou mais e produzirá $\mathrm{P}_{4}$ embora em menor quantidade que o CL normal. Freqüentemente é maior que o corpo luteo fisiológico. Os cistos luteínicos, folículos anovulatórios (parcialmente luteinizados) são basicamente associados ao anestro, como o são os cistos foliculares durante o puerpério (KOZICKI, 1982). Os cistos foliculares estão presentes com mais freqüência em vacas com elevada produção de leite (GRUNERT, 1988), e naquelas que tiveram complicações no parto. Em torno da metade das vacas com cisto precoce (isto é na fase de puerpério intermediário), conseguem ter a espontânea involução dos cistos (KOZICKI, 1982; GRUNERT, 1988).

\section{Folículos Ovarianos}

A performance reprodutiva da vaca no período do pós-parto, afeta a eficiência da produção de leite no rebanho, influindo sobre o intervalo parto/inseminação artificial. $\mathrm{O}$ serviço de inseminação é muito afetado pela eficiência da detecção do cio e da taxa de anestro no rebanho. A taxa de anestro é influenciada pelo intervalo pósparto até o retorno do desenvolvimento de folículos dominantes e da exposição destes folículos dominantes à frequência dos pulsos do LH (ROCHE et al., 1992).

Após a parturição há temporária supressão do folículo ovariano dominante, o qual ocorrerá em outro período reprodutivo do animal, como por exemplo no proximo ciclo estral (ROCHE e BOLAND, 1991). Os fatores que comandam o desenvolvimento do folículo dominante envolvem o recrutamento de uma série de folículos que tornamse gonadotrofinas-dependentes para o seu desenvolvimento. Desta série de folículos recrutados, um único folículo é selecionado para o crescimento, tornando-se o folículo dominante (= folículo único maior que $10 \mathrm{~mm}$ de diâmetro, o qual suprime o crescimento de outros folículos). $\mathrm{O}$ folículo dominante ovula, se o seu grau de desenvolvimento coincidir com a regressão do corpo lúteo, ou torna-se atrésico se coincidir com a presença de um corpo lúteo ativo (=elevada $\mathrm{P}_{4}$ ). Após o parto, o desenvolvimento folicular envolve o crescimento e a regressão de folículos menores que $8 \mathrm{~mm}$ de diâmetro até a detecção do primeiro folículo dominante, que ocorre em média nas vacas no $11,5^{\circ}$ dia p.p. O crescimento padrão do $1^{\circ}$ folículo dominante p.p., implica em aumento dele próprio de $2-3 \mathrm{~mm} /$ dia de diâmetro. $\mathrm{O}$ número de pequenos folículos (de 3 a $5 \mathrm{~mm}$ ), varia entre 2 e 5 por dia (ROCHE et al., 1992). Contrastando com os bovinos de leite onde a maioria das vacas ovulam o $1^{\mathrm{o}}$ folículo dominante, o destino do folículo dominante nos bovinos de corte com cria ao pé é diferente. MURPHY et al., (1990) relataram que vacas de corte com razoável condição corporal desenvolviam o primeiro folículo dominante dentro dos 14 primeiros dias após o parto, mas ficou evidente que somente $11,1 \%$ ovulavam esse $1^{\circ}$ folículo dominante e o percentual restante tornavase atrésico. Deste modo concluiu-se que o prolongado período de anestro p.p. no gado de corte deveu-se mais à falha da ovulação da maioria dos primeiros folículos dominantes (falta do pico de $\mathrm{LH}$ ), do que ao atraso no desenvolvimento do $1^{\circ}$ folículo dominante p.p. (ROCHE et al., 1992).

\section{Ovulação}

A hipófise anterior sofre diminuição do conteúdo de LH e FSH no período final da gestação e no inicio do período puerperal, devido ao drástico feedback negativo das elevadas concentrações de estrógenos no final da gestação (NETT, 1987). A concentração de GnRH liberado do hipotálamo é fisiológica mas a hipófise anterior é menos sensível ao GnRH-indutor da liberação do LH no puerpério precoce. As concentrações de FSH são baixas durante breve período após a parturição (SCHALLENBERGER, 1985) e posteriormente eleva-se, presumindo-se que esta elevação de FSH venha a iniciar o recrutamento e a seleção de um folículo dominante. Desta forma, o evento principal para a determinação de quando deve ocorrer a ovulação é a presença e a exposição de um folículo dominante frente à correta freqüência da pulsação de LH. A inadequada freqüência pulsátil de LH, resulta em baixa produção de estrógenos no folículo. Deste modo, não ocorre o aumento de estrógeno na fase de proestro. Como o folículo dominante está no estágio final da diferenciação, ele será levado à atresia, devido à inadequada freqüência pulsátil de LH. A ovulação do folículo 
dominante sòmente ocorre, quando ocorre a pulsação de LH a cada 40-60 minutos para estimular ao máximo a produção de estrógenos e acontecer o feedback positivo para a vinda da onda do LH e FSH. (ROCHE et al., 1992). Deste modo, o FSH é o principal responsável pelo recrutamento e seleção do folículo dominante, e a exposição de um folículo estrogenicamente dominante ativo frente às freqüências dos pulsos de LH é a chave para a maturação final e a ovulação. Portanto, fatores que suprimam as freqüências pulsáteis de LH no período do puerpério irão protelar a $1^{\mathrm{a}}$ ovulação. Por exemplo, os estímulos mamários de sucção e a presença de bezerro, suprimiriam a liberação de LH devido aos efeitos da liberação dos opióides (MYERS et al., 1989). A remoção do bezerro que está sendo amamentado ou a redução da freqüência das mamadas aumenta a freqüência pulsátil de LH, mas não são meios práticos para se conseguir uma ovulação mais precoce no gado de corte.

A nutrição é um fator que está provavelmente envolvido na regulação da secreção hipotalâmica de GnRH e portanto na freqüência pulsátil de LH. A interação entre o balanço energético e a secreção pulsátil de LH no puerpério precoce de vacas (CANFIELD e BUTLER, 1990) é indicativo de que a freqüência pulsátil de LH aumenta com o intervalo pos-parto antes de ocorrer a primeira ovulação. A nutrição pode também afetar o diâmetro do folículo dominante (MURPHY et al., 1991) e a baixa condição corporal do animal resultará em grandes folículos com pouca atividade de biossíntese de estrógenos " in vitro" (PRADO et al., 1990). Deste modo, a combinação dos acentuados efeitos da prenhez sobre a síntese e a liberação de LH assim como os efeitos supressivos, seja pelo ato de mamar ou pelo baixo nível nutricional, influenciam significativamente a freqüência pulsátil no puerpério precoce levando o folículo dominante mais a tornar-se atrésico do que à ovulação (ROCHE et al., 1992).

\section{LH e FSH}

As mudanças hormonais no pós parto podem ser resumidas como se segue: imediatamente após o parto não há fatos claros e definidos da atividade de FSH e LH independente de amamentação, lactação ou outras funções. Segundo isto, os níveis de FSH aparecem primeiramente no plasma seguido pelo LH. Em vacas lactantes, devido ao aumento da liberação de GnRH, há aumento nos níveis basais de LH juntamente com aumento da freqüência e amplitude dos pulsos de LH, culminando com a onda ovulatória. Após a ovulação há uma fase luteal a qual pode ter normal comprimento com o retorno ao estro após 18 a 24 dias ou pode ser muito mais encurtada, (KOZICKI, 1982). Esta fase luteal mais curta, provavelmente ocorre devido ao inadequado desenvolvimento pré-ovulatório do folículo, de modo que ele ou torna-se luteinizado não ocorrendo ovulação ou a luteinização é inadequada e insuficiente. Essas curtas fases luteais incidem em maior percentual quanto mais precoce for o retorno da atividade ovariana após o parto, atingindo $100 \%$ de incidência quando ocorrer do 0 ao $5^{\circ}$ dia p.p., $60 \%$ quando ocorrer entre $10-15^{\circ}$ dia e $10 \%$ quando do $25-30^{\circ}$ dia p.p. (TERQUI et al., 1982).

\section{Outros Orgãos Envolvidos}

Outros órgãos endócrinos estão envolvidos no controle da função ovariana no puerpério. $\mathrm{O}$ útero exerce influência, uma vez que a maioria das ovulações que acontecem após o parto ocorrem no ovário correspondente ao corno não-grávido (GIER e MARION, 1968). Sabe-se também que os metabólitos da prostaglandina (PGFM) normalmente retornam aos níveis normais antes da $1^{\mathrm{a}}$ ovulação pós parto (THATCHER, 1986). Semelhantemente o eixo útero-ovariano exerce efeito inibitório sobre a secreção hipofisária de LH durante o puerpério precoce (SCHALLENBERGER et al., 1982).

$O$ córtex da adrenal tem importante função no retorno do estro após o parto. A administração de ACTH (LIPTRAP e McNALLY, 1976) e útero (DA ROSA e WAGNER, 1981) suprime a secreção de LH . Estímulos dos tetos e a retirada do leite pela ordenha, causam elevação nos glicocorticóides (SCHAMS, 1976), os quais provavelmente explicam os efeitos inibitórios da amamentação sobre o retorno da atividade ovariana após o parto. Tem sido demonstrado que a glândula mamaria exerce influência nesse processo endócrino. Além disso, nas vacas que amamentam, o período do anestro é prolongado, principalmente em vacas que recebem inadequados ganhos de peso durante o último trimestre da gestação e nos 2 primeiros meses após o parto.

\section{Afecções}

Diversas pesquisas foram levadas a efeito a respeito dos métodos hormonais para acelerar o $1^{\circ}$ estro e a ovulação. Nos bovinos de leite a $1^{\mathrm{a}}$ ovulação p.p. ocorre em torno da $2^{\mathrm{a}} / 3^{\mathrm{a}}$ semana e o $1^{\mathrm{o}}$ estro visível é normalmente observado 2 a 3 semanas após. Em torno de $15 \%$ dos animais são observadas anormalidades da atividade ovariana (cisto folicular ou luteínico) durante os 2 meses p.p. Houve maior incidência dessas afecções entre 25 e 38 dias após o parto e isto evidentemente prolongou o período da nova concepção (KOZICKI, 1982). A 
mais importante causa da ovulação retardada em vacas é a irregular freqüência pulsátil de GnRH no puerpério precoce, devido à ausência dos efeitos de feedback negativo da concentração de progesterona. $\mathrm{O}$ GnRH foi muito utilizado no p.p. para induzir a ovulação nos animais em anestro nos experimentos, nos casos em que não se sabia o estado folicular dos animais, mas sua eficiência foi baixa. Embora um variado numero de vacas ovule após administração de GnRH, a condição corporal da vaca e o estágio folicular no momento do tratamento com GnRH, têm sido os fatores da baixa resposta. Parece que a associação de GnRH mais progesterona demonstram melhores efeitos que somente o GnRH (ROCHE et al., 1992).

\section{GnRH}

Para vários pesquisadores, o GnRH administrado no período intermediário tem melhorado a fertilidade de vacas com involução uterina deficiente. Para melhorar a fertilidade do animal o GnRH deve ser administrado em torno do $12^{\circ}$ ao $18^{\circ}$ dia p.p. para reduzir o período entre partos (OLSON et al., 1986). No entanto KOZICKI et al., (1996) trabalhando com bovinos leiteiros no puerpério precoce, não puderam confirmar tais observações. Porém, ao pesquisarem os efeitos do GnRH no puerpério tardio ( $35^{\circ}$ dia p.p.) pode-se observar melhorias quanto à visualização do estro, melhor índice de ovulação bem como melhor desenvolvimento folicular no grupo tratado com GnRH (KOZICKI, 1991).

\section{Progestágenos}

A progesterona tem sido usada para melhorar os sinais visíveis do estro e a ocorrência de ciclos curtos depois da $1^{\mathrm{a}}$ ovulação pós parto. No gado de leite livre de agentes estressantes, foram conduzidos experimentos no sentido de determinar o intervalo parto $/ 1^{\circ}$ estro, fazendo-se tratamento de 12 dias com progesterona intravaginal (progesterone release intravaginal device-PRID) e $10 \mathrm{mg}$ de estradiol (ROCHE, 1976a, b). Vacas paridas há mais de 30 dias tiveram 95\% (elevada taxa) de resposta de estro após a remoção do PRID, ao passo que vacas paridas há menos de 30 dias p.p. tiveram $45 \%$ de resposta de cio, após a remoção do PRID.

Em outro experimento, examinou-se o efeito do PRID sobre a indução do estro e a ovulação no puerpério precoce (MURPHY et al., 1989). Trinta vacas tiveram seus ovários monitorados no $10^{\circ}$ dia p.p., e foram alocadas a um grupo controle e outras receberam o PRID por 10 dias. A ocorrência da $1^{\text {a }}$ ovulação prolongou-se devido ao tratamento com o PRID (22 dias) quando comparado com o lote controle (15 dias), havendo retardo da $1^{\mathrm{a}}$ ovulação até que o PRID fosse removido. Entretanto, o tratamento com o PRID significativamente antecipou o $1^{\circ}$ cio visível p.p. (21 dias) contra 34 dias no grupo controle. Ficou claro por esses resultados que a $\mathrm{P}_{4}$ exógena, tem influência sobre o cio e sobre a ovulação no puerpério. A incidência de ciclos curtos após o tratamento com a $\mathrm{P}_{4}$ foi também significativamente reduzida.

$\mathrm{O}$ percentual de incidência de anestro no bovino de leite no puerpério precoce aumentará quando os animais forem submetidos a condições desequilibradas de nutrição. Este problema pode ser maior nos animais primíparos, nos animais com elevada produção leiteira ou em vacas propensas às doenças metabólicas. Esses animais tem ovários pequenos, inativos e duros baseado em diagnostico por palpação retal. Consequentemente, a deficiência nutricional pode causar prolongamento do desenvolvimento de folículos dominantes ou subdesenvolvimento de folículos dominantes que são menores e com menos estrógenos ativos. Deste modo, os animais privados de boa nutrição requerem estímulos gonadotróficos como prétratamento com progesterona, demonstrado pelas pesquisas de MACMILLAN e DAY (1987). Eles demonstraram que $48 \%$ das vacas leiteiras com anestro receberam progesterona $(\mathrm{P})$ intravaginal durante 7 dias e foram inseminadas dentro de uma semana após remoção da $\mathrm{P}$, em contraposição com apenas $22 \%$ das vacas controles. A injeção de 400 a 800 UI de PMSG aumentou a resposta ao estro entre 70 a $85 \%$ após remoção da progesterona. A eficiência deste tratamento variou entre os rebanhos, ano, estação e grau de consanguinidade.

No gado de corte, tratamento com P durante 712 dias produziu melhores índices de prenhez quando comparado com 2 injeções de $\mathrm{PGF}_{2 \alpha}$ porque $30 \%$ das vacas tinham ovários inativos no inicio do tratamento (ROCHE, 1976a, b). Nos animais paridos há menos que 60 dias, o PMSG em associação com $\mathrm{P}$ aumentou significativamente a taxa de prenhez quando comparado com o tratamento isolado com a P (MULVEHILL e SREENAN, 1977).

Em outro experimento em larga escala foi demonstrado que o índice de prenhez deveu-se à qualidade do sêmen (variação de 35 a $67 \%$ de índice de prenhez) e à competência do inseminador (variação de 35 a $63 \%$ de prenhez) (DAY et al., 1992) muito mais que a idade ou ao intervalo p.p. ou ao estado ovariano dos animais no inicio do tratamento. Desse modo, o bom manejo das vacas de corte paridas há menos de 60 dias, utilizando-se associação de progesterona com PMSG exige elevada qualidade do sêmen e competência do inseminador para se chegar a bons resultados. 


\section{Fatores Influentes}

Dentre os fatores que influenciam a involução uterina ARTHUR et al., (1989) salientam: 1. Idade. Muitos pesquisadores acham que a involução uterina é mais rápida em primíparas do que nas pluríparas. 2. Estação do ano. Se houver alguma influência da estação do ano, a involução uterina é mais rápida na primavera e no verão. 3. Amamentação e ordenha. Os resultados são contraditórios, mas pode ser que haja influência racial. 4. Clima. Há evidência de que o estresse calorico pode acelerar ou inibir a velocidade da involução. 5. Anormalidades peripartais. Distócia, retenção de placenta, hipocalcemia, cetose, gestação gemelar, metrite, cesariana, fetotomia podem, no geral, prolongar mais a involução uterina. 6. Maior movimentação dos animais no puerpério. Reduz o período de involução uterina e melhora a atividade ovariana (KOZICKI, 1982).

Alguns fatores, segundo ARTHUR et al. (1989), exercem influência sobre o retorno da atividade ovariana p.p.: 1. Nutrição. Importante para vacas de leite e corte. Inadequados teores de energia durante o período seco e após o parto inibem a atividade ovariana p.p. 2. Amamentação intensa e freqüência de ordenha. Quanto maior a freqüência e a intensidade de amamentação, maior será o período de aciclicidade. 3. Clima. Vacas nos países tropicais demonstram maior retardo à ciclicidade do que nos climas temperados, provavelmente devido ao estresse calórico. 4. Puerpério com problemas.

Experimentos relacionados à nutrição mostram que a hipofunção ovariana sob condições de dietas restritas em energia, reduz a capacidade de resposta dos ovários frente ao $\mathrm{LH}$, embora existam níveis circulantes de LH (MORROW, 1980). Em experimento, um grupo de novilhas prenhes foi nutrido com equilíbrio energético e outro grupo recebeu elevados níveis energéticos. Concluiu-se que o intervalo entre a $1^{\mathrm{a}}$ ovulação p.p. e o estro visível foi mais curto no grupo com equilíbrio alimentar e ocorreu menor \% de retenção de placenta e metrite neste grupo do que no grupo que recebera elevados níveis energéticos na alimentação, concluindo-se que alimentação em excesso também não é o ideal (MORROW, 1980). Elevada produção de leite pode também ter efeito adverso sobre a fertilidade. Num estudo com 204 vacas o intervalo do parto/concepção e $o n^{\circ}$ de serviços/concepção aumentou assim que a produção de leite elevou-se. Estes efeitos foram verificados principalmente em animais com lactação de 7272 kg ou superior. É sabido que rebanhos com elevada produção leiteira tem um equilíbrio energético negativo durante o inicio da lactação, porque eles não consomem suficiente alimento para equilibrar os nutrientes necessários para essa produção elevada (MORROW, 1980).

Outro fato é que, o índice de prenhez é mais elevado em vacas que ganham peso na época da inseminação, do que as que estão perdendo peso nesta ocasião. Em um estudo feito na Inglaterra, vacas que tiveram ganho de peso após o parto, obtiveram a taxa de concepção de $78 \%$ ao $1^{\circ}$ serviço, ao passo que animais que haviam perdido peso durante o puerpério, somente 16\% ficaram prenhes. Nos Estados Unidos vacas que ganharam peso durante 30 e 90 dias após o parto, tiveram uma taxa de concepção de $64 \%$ ao $1^{\circ}$ serviço, ao passo que as vacas que perderam peso no mesmo período tiveram taxa de prenhez de $46 \%$. Segundo este experimento, o maior problema com a perda de peso ocorreu em primíparas de 2 anos com elevada produção leiteira, porque elas ainda necessitavam de nutrientes para o seu próprio crescimento, para manutenção e ainda para a lactação. Isto significa que animais que parem e ainda não completaram seu desenvolvimento corporal (típico de novilhas cobertas muito cedo), carecem de muito mais cuidados quanto aos aspectos nutritivos, para completarem seu desenvolvimento, produzirem leite e ainda reproduzirem (MORROW, 1980). Num estudo na Nova Zelândia com 1028 novilhas de 2 anos e em anestro, $85 \%$ tinham ovários inativos no $60^{\circ}$ dia p.p. em contraposição com apenas $47 \%$ de ovários inativos das vacas com 4 anos de idade. Isto indica que novilhas paridas em torno dos 2 anos de idade têm forte tendência a ter problemas de atividade ovariana no pós parto. Por isto os cuidados deverão ser redobrados.

\section{Anestro}

O anestro p.p. nos bovinos é um evento fisiológico normal onde ocorre a involução uterina e os ovários indicam sua atividade ovariana. $\mathrm{O}$ anestro torna-se patológico quando ele ultrapassa o período considerado para uma média aceita. A duração do intervalo do anestro, em média, é influenciado pela idade, raça, fatores ambientais e genéticos (HOPKINS, 1986). Para se conhecer as causas do anestro p.p., faz-se necessário entender o mecanismo do eixo hipotálamo-hipófise-ovário e iniciar a terapia para promover o estro. Para simplificar, em determinado momento há o aparecimento do $\mathrm{FSH}$, o qual promove o crescimento folicular que pode ser detectado em torno do $9^{\circ}$ ao $15^{\circ}$ dia p.p. na vaca leiteira. Os níveis plasmáticos do estradiol são rigorosamente sincronizados com as ondas de FSH e o crescimento folicular. A onda de estradiol interage com os centros neuroendócrinos, os quais aumentam a sensibilidade ao GnRH. Consequentemente, os níveis de LH aumentam o numero de picos e a amplitude dos picos com fortes tendências de aumentar durante as 2 primeiras semanas p.p.. Isto tem correlação 
com o fato de que a quantidade de LH hipofísário, aumenta após o parto e a sensibilidade do LH frente ao $\mathrm{GnRH}$, retorna cerca de 8 a 10 dias. Em aproximadamente 2 a 3 semanas p.p., os níveis de LH são capazes de induzir a ovulação. O CL desta $1^{\mathrm{a}}$ ovulação p.p. possui um baixo conteúdo de $\mathrm{P}$ e resultará em meia vida mais curta acarretando geralmente estro silencioso, normalizando nos cios que vão se suceder. Os fatores que podem modificar este decorrer de eventos podem ser divididos em três categorias: efeito da lactação, efeitos nutricionais e efeitos das doenças orgânicas. $\mathrm{O}$ anestro pode ser devido à combinação destes três fatores, tornando a terapia mais difícil. Animais de $1^{\mathrm{a}}$ cria, seja de corte ou de leite, têm geralmente anestro prolongado devido à demanda de continuar seu crescimento e manter a lactação como já foi anteriormente citado (HOPKINS, 1986). O exame clínico do animal tipicamente em anestro revela ovários que vão de pequenos e firmes sem estruturas palpáveis (isto é, ovários duros e lisos) até aqueles que tem múltiplos folículos de tamanho médio (de 5 a 10 $\mathrm{mm}$ ). Embora a maioria dos casos de anestro possa se resolver por si (desde que a alimentação esteja equilibrada), ele conduzirá a prolongados intervalos pós-partais, os quais não são econômicos.

A lactação tem sido mostrada como causa de prolongamento do período de anestro p.p.. Num experimento fez-se três grupos de animais com dieta igual e perfeitamente equilibrada. $\mathrm{O} 1^{\circ}$ grupo foi mastectomizado, o $2^{\circ}$ grupo com mamas intactas não amamentando e o $3^{\circ}$ grupo animais intactos amamentando. Demonstrou-se que no grupo que amamentava, a concentração media de LH plasmático diminuiu e aumentou o comprimento do intervalo à secreção de LH. Isto evidentemente impediu a $1^{\mathrm{a}}$ ovulação p.p. e bloqueou o retorno da ciclicidade ovariana (HOPKINS, 1986). Comparações entre vacas ordenhadas e vacas que amamentavam demonstraram ser os níveis circulantes de cortisol um possível componente bloqueador da secreção de LH. Os corticóides são tidos como depressores das ondas de LH e diminuem a sensibilidade da hipófise frente ao GnRH. Tanto é que os níveis de cortisol plasmático são muito maiores nas vacas que amamentam o bezerro ao pé e menores em animais ordenhados por maquina em duas ordenhas diárias. Além disso, os níveis de cortisol são mais elevados em vacas com elevada produção, quando comparadas com as de baixa produção de leite. A tendência é de que as vacas com elevada produção leiteira, tenham período mais prolongado de anestro do que as outras.

\section{Energia}

Sob o ponto de vista nutricional, há uma relação geral entre a nutrição balanceada fornecida e o anestro. $\mathrm{O}$ balanço energético que é a diferença entre a energia liquida necessária e a energia liquida consumida, parece ser sensível indicador do comprimento do período de anestro. O balanço energético está muito proximo da produção de leite, que é individualmente o ponto mais crucial no pós parto da vaca. A vaca, individualmente, tem finita capacidade de receber alimentos. Uma vez que há variação da capacidade e do metabolismo endógeno entre os animais, o aporte diário de alimentos ou as mudanças no peso corporal, principalmente em animais no crescimento, dificultam o diagnóstico da duração do período de anestro p.p. (HOPKINS, 1986)

A ovulação tem sido associada com o retorno do equilíbrio alimentar do animal frente ao balanço energético negativo. Há contudo animais que ovulam mesmo frente a um balanço energético negativo. $\mathrm{O}$ anestro p.p. pode ser causado pelo simples fato de alimentação deficiente, principalmente quando pobre em energia. Animal com baixa produção deve ciclar por primeiro, mas a extensão do período aberto entre parto/concepção será maior.

\section{Infecções}

Outro grande problema que se apresenta juntamente com o aparecimento do anestro p.p. são as doenças primarias do útero. A vaca terá o período de anestro prolongado quando tiver retenção de placenta, metrite, gestação gemelar, hidropisia dos anexos fetais (HOPKINS, 1986) ou doenças debilitantes crônicas tais como frieiras, problemas de abomaso ou doenças de caráter geral. Com respeito às complicações que se apresenta nos bovinos no período do puerpério deve-se destacar que entre o $1^{\circ}$ e $14^{\circ}$ dia p.p. ocorre a retenção da placenta e a metrite puerperal. A metrite puerperal varia de branda a severa e é ameaça à vida da parturiente. Severas formas de metrite tais como: a metrite séptica, tóxica ou gangrenosa, acarretam o prolongamento da involução do útero. Este período é crítico, porque as doenças que ocorrem nesta fase podem resultar em doenças crônicas e infertilidade mais tarde. A retenção placentária é problema bastante comum no puerpério precoce de bovinos e aumenta o risco de infecções uterinas (OLSON et al., 1986). A questão de remover manualmente a placenta retida não está resolvida. Alguns pesquisadores relatam que é necessário que seja removida, porque ela funcionaria em primeiro lugar, como corpo estranho e segundo poderia impedir a drenagem de conteúdos uterinos como por exemplo as secreções uterinas loquiais abundantes nesta época. Entretanto, excessiva manipulação é muito estressante para a vaca e pode traumatizar o endométrio, carúnculas, tecidos 
subendometriais e consequentemente prolongar muito mais a involução do que se deixasse a placenta, sem molestar o animal com a retirada. Diversos estudos foram feitos mostrando a diminuição da fertilidade em vacas nas quais a placenta fora removida e outros estudos demonstraram haver pouco beneficio em se retirála. De modo geral, é aceito que a remoção é contraindicada, principalmente se a retenção de placenta (RP) estiver complicada com metrite séptica e tóxica, porque nestas vacas o útero é muito friável e mais sujeito a danos. Entretanto, o exame higiênico vaginal deve ser conduzido para determinar se a placenta está ou não solta no interior da cavidade uterina. Se está solta, deve ser delicadamente removida. Não há melhor meio para tratar todas as vacas com RP, ou seja não há tratamento padrão que deva ser instituído para todos os animais com $\mathrm{RP}$, devido exatamente à variação da quantidade e à variação dos graus de gravidade do processo. Por isto, deve-se considerar o seguinte: a facilidade de remoção, a quantidade de traumas já pré-existentes e a ocorrência de problemas metabólicos ou doença infecciosa. O ideal são os cuidados individuais, com a decisão final baseada na avaliação da situação que se apresenta ao veterinário prático. Entretanto, em grandes rebanhos, tratamento de rotina deve ser estabelecido para que possa ser exequível com a rotina da fazenda. A tendência atual é não realizar a remoção. Entretanto, o objetivo de impedir o crescimento bacteriano e estabelecer a drenagem uterina deve ser direcionado pelo bom senso do técnico e utilizar agentes antimicrobianos bem como realizar a tração delicada quando indicada (OLSON et al., 1986). Tracionando ou não a placenta, o fato é que deve ser tratada com 2 a 6 g de tetraciclina, o antibiótico de eleição para a terapia intrauterina neste período puerperal. A área vulvar e as luvas que o profissional for usar devem ser lavadas e desinfectadas antes de administrar antibiótico que de preferência deve ser sob a forma de velas uterinas. Ao se optar pela infusão uterina cuidar muito com a ponta da pipeta, pois há muito risco de ocasionar abcesso do corpo uterino devido a traumas nesta área. $\mathrm{O}$ tratamento deve ser imediatamente iniciado em vacas com as membranas fetais retidas há mais de 12 horas p.p. e deve ser continuado diariamente até que as membranas fetais sejam expulsas. Cuidar para que a remoção da placenta seja muito delicada. Se for usada muita força trará sérios prejuízos para a futura fertilidade. Muitas fazendas tem obtido sucesso realizando o tratamento a cada 2 ou 3 dias, mas isto depende muito da gravidade do caso. Vacas com metrite puerperal devem ser divididas em 2 categorias: aquelas que tem comprometimento sistêmico e as que não tem este comprometimento.
Se a vaca estiver com anorexia, deprimida e febril, deve ser tratada tanto local como sistemicamente com elevadas doses. A maioria dos germens que causam metrite puerperal séptica são susceptíveis à penicilina, de modo que este antibiótico é o de eleição para o tratamento sistêmico (OLSON et al., 1986). Clinicamente, doses de 4 a 5 g/animal dão em bom resultado. E para o tratamento intrauterino da metrite puerperal, usar as tetraciclinas em torno de 4 g cada vez.

OLSON et al., (1986) relatam dois períodos após o parto, sendo o intermediário após o parto no qual o tipo de descarga uterina nessa fase é purulento. É comum identificar vacas com infecção nesse período. Um exame ginecológico poderá facilmente identificar, uma vez que há frequentes descargas de secreção purulenta. $O$ tratamento intrauterino deverá ser feito com $1 \mathrm{~g}$ de tetraciclina em 20 a 40 $\mathrm{ml}$ de água estéril ou solução fisiológica, durante 3 dias seguidos. E o segundo seria o período pós ovulatório no qual podem ocorrer nesse período a piometra ou a metrite causadas freqüentemente por miscelânea de Corynebacterium pyogenes e germens gram-negativos anaeróbios. O primeiro objetivo em caso de piometra é lisar o CL e estimular a contratilidade uterina para estimular a drenagem do útero. Estrógenos (ECP) tem sido usado com sucesso em 50 a $60 \%$ dos casos. Mais recentemente tem sido usado a $\mathrm{PGF}_{2 \alpha}$ com sucesso de 80 a $90 \%$ dos casos. Vacas tratadas entre o $21^{\circ}$ e o $35^{\circ}$ dia p.p. parecem situar-se na melhor média de tratamento e fertilidade do que quando os animais são tratados 2 semanas após este período. As vacas problemas deste grupo, que tornam-se prenhes o fazem somente após o $60^{\circ}$ dia após o tratamento em função do prolongado tempo necessário à cura do útero. A função do tratamento local da piometra não está bem definido. Sabe-se no entanto que o uso de nitrofurazona (furacin) intrauterino após a evacuação do fluido da piometra diminui a fertilidade. Outro fato muito importante no tratamento é que não se deve usar excesso de volume do veículo para o antibiótico. Em nossa opinião, deve-se usar, não mais do que $35 \mathrm{ml}$ de água estéril, sob pena de acúmulo de liquido na mucosa endometrial, acarretando degeneração deste nobre epitélio. Se for para usar antibiótico deve a penicilina ser usada como medicamento de eleição nesse período. É comum também ocorrer metrite no período pósovulatório. Aqui também a penicilina é o antimicrobiano de eleição. Infusão intrauterina de 1 a 2 milhões de UI, é suficiente para manter o nível terapêutico de antibiótico no lúmen uterino por 24 horas no mínimo (OLSON et al., 1986).

Sobre o tratamento profilático, vacas com complicada retenção de placenta tem elevado risco 
de ter o complexo metrite-piometra. Diversos tratamentos profiláticos para estes casos de elevado risco foram testados, com resultados muito inconstantes. Alguns estudos indicam que a rotineira administração de antimicrobianos pode ser prejudicial à fertilidade, outros demonstram não haver melhora e outros ainda demonstram que a fertilidade de vacas tratadas aproxima-se da fertilidade das vacas que geraram sem complicações. Certamente, algum tratamento deve possuir lógica farmacológica e base terapêutica. Os benefícios oriundos da profilaxia com antibióticos podem variar de rebanho para rebanho. Consequentemente, o tratamento a ser instituído deverá ser feito após cuidadosa avaliação de cada situação. A profilaxia antibiótica é mais benéfica e indicada, quando o índice de infecção genital inicial for elevado. Entretanto, em fazendas com bom manejo, os antibióticos devem ser usados o mínimo possível. Um único tratamento com antibiótico no puerpério precoce raramente dará bom resultado principalmente em se tratando de RP. Consequentemente, muitos tratamentos deverão ser feitos com antibiótico da família das tetraciclinas e administrado diariamente até que a placenta seja expulsa (OLSON et al., 1986). Usar estrógenos na terapia da RP é ineficaz e pode prejudicar os animais.

Agentes luteolíticos e estrógenos estimulam a evacuação da piometra, com vantagem para a $\mathrm{PGF}_{2 \alpha}$. Os agentes luteoliticos tem a vantagem de não se precisar rejeitar o leite, ao passo que os antibióticos comprometem a venda do leite. (OLSON et al., 1986). O tratamento da metrite e de piometra mal conduzidos pode trazer graves consequências. Manipulações vigorosas do trato genital podem ocasionar aderências da genitália. Manipulações obstétricas e a remoção da RP estão freqüentemente implicadas neste processo. Excessiva irrigação intrauterina pode causar ruptura do útero. Aplicações intrauterinas com substâncias irritantes, principalmente em útero traumatizado e lacerado, causa freqüentemente reação cicatricial local diminuindo a fertilidade. Remoção traumática da RP permite a instalação de germens na parede uterina causando abcesso da parede, podendo levar ao processo de piemia. Também, traumatismos com a pipeta podem ocasionar abcessos. Os fluidos da irrigação uterina (isto é, grandes volumes de líquido), podem, no puerpério precoce, fluir por ascendência às salpinges e causar salpingite e bursite ovariana. Devido à rotina dos tratamentos em grandes rebanhos, deve ser considerada a resistência dos germens perante os antibióticos e por isto este tratamento deve ser seguidamente reavaliado bem como a escolha do antibiótico (OLSON et al., 1986).

\section{Redução do Período de Serviço}

Há tempos atrás pensava-se que a reprodução mais precoce que 60 dias p.p. seria prejudicial à futura vida reprodutiva do animal. Uma verificação mais profunda deste conceito demonstrou que esta afirmativa não era baseada em experimentos, mas tão somente em opiniões muito primárias em termos científicos. Estudos que datam já de algum tempo davam conta de que o $1^{\circ}$ serviço p.p. realizado entre o 60 e 90 dias p.p., possuia os mais elevados índices de prenhez (WHITMORE, 1980). Baseados nisto, centrais de inseminação e pesquisadores propuseram, durante muito tempo, que os animais deveriam ser inseminados somente após o $60^{\circ}$ dia p.p. $\mathrm{Na}$ década de 60 os pesquisadores começaram a se perguntar se a reprodução mais precoce após o parto traria mesmo as desvantagens propostas naquela época. Começou-se então a fazer grandes e numerosos experimentos neste sentido para verificar seus efeitos. Num experimento em 36000 vacas controladas verificou-se que fazendo a inseminação em torno do $40^{\circ}$ dia p.p. ao invés do $60^{\circ}$ dia p.p., havia aumento de 0,08 serviços por vaca prenhe, mas em compensação o intervalo entre partos baixava em 15 dias. Em Israel mostrou-se que a reprodução mais precoce após o parto resultou em menor intervalo entre-partos. A média de intervalo do parto a $1^{\mathrm{a}}$ IA decresceu de 78 dias no primeiro ano do experimento, para 61 dias em média após o $4^{\circ}$ ano de instalação deste programa. Isto reduziu o intervalo entre partos de 385 para 376 dias. Deste modo, para cada dia a menos, após o parto, que o animal fora inseminado, o intervalo entre partos foi mais curto em 0,54 dia. Em experimento realizado em Wisconsin, 75 vacas leiteiras foram divididas em 2 grupos: grupo 1, vacas que eram inseminadas no $1^{\circ}$ estro visível p.p. (IA precoce) e o $2^{\circ}$ grupo era inseminado no $1^{\circ}$ cio após o $74^{\circ}$ dia p.p. (IA tardia). $\mathrm{O}$ estudo foi conduzido durante 7 anos consecutivos. O rebanho foi monitorado semanalmente via palpação retal (WHITMORE, 1980). As conclusões foram de que a inseminação artificial precoce após o parto pode ser definitivamente usada para encurtar o período entre partos e que ela não ocasionava prejuízos à futura vida reprodutiva das vacas. $\mathrm{O}$ criador pode assim comparar economicamente os custos de abreviar o intervalo entre-partos.

Estudos na Carolina do Norte, Estados Unidos, demonstraram que houve diminuição média de 2,4 $\mathrm{kg}$ de leite para cada dia a mais em aberto após o parto. Os dias abertos não afetaram as novilhas da mesma maneira que aconteceu com vacas mais velhas. Baseado neste estudo os autores do projeto sugerem que seria ótimo intervalo entre partos de 13 meses para as novilhas de $1^{\mathrm{a}}$ cria e de 12 meses para vacas de $2^{\mathrm{a}}$ e $3^{\mathrm{a}}$ cria, objetivando a produção 
máxima de leite (WHITMORE, 1980).

O período ótimo em extensão para secagem das vacas de leite antes da parturição é de 40 a 45 dias. Período seco menor do que 40 dias, resulta em decréscimo da longevidade da produção leiteira futura, enquanto que período seco mais longo do que 45 dias reduz a produção diária de leite. Conclui-se desses experimentos que vacas inseminadas mais cedo após o parto tem o intervalo entre partos mais curto e por isso aumenta a produção leiteira. $\mathrm{O}$ único efeito desvantajoso seria o de aumentar o número de serviços por concepção, quando os animais são inseminados em torno do $40^{\circ}$ dia p.p., ao invés de 60 dias p.p. (WHITMORE, 1980). A recomendação veterinária é a de que animais em bom estado nutricional e ginecológico no $30^{\circ}$ dia p.p., devem ser inseminados em torno da $6^{\mathrm{a}}$ semana após o parto.

\section{REFERÊNCIAS BIBLIOGRÁFICAS}

ARTHUR, G.H.; NOAKES, D.E.; PEARSON, H. Veterinary reproduction and obstetrics, Bailliere Tindall, London, $6^{\text {a }}$ ed., p. 161-171, 1989.

BOLINDER, A.; SEGUIN, B.; KINDAHL, H.; BOULEY, D.; OTTERBY, D. Retained fetal membranes in cows; Manual removal versus nonremoval and its effect on reproductive performance. Theriogenoly. 30:45-56, 1988.

BOSU, W.T.K.; LIPTRAP, R.M.; LESLIE, K.E. Peripartal changes in plasma progesterone and 15keto-13, 14-dihydro-prostaglandin $\mathrm{F}_{2 \alpha}$ concentrations in Holstein cows with and without retained fetal membranes, Anim. Reprod. Sci. 7:497-510, 1984.

BOSU, W.T.K.; PETER, A.T. Evidence for a role of intrauterine infections in the pathogenesis of cystic ovaries in postpartum dairy cows. Theriogenology. 28:725-736, 1987.

CANFIELD, R.W.; BUTLER, W.R. Energy balance and pulsatile LH secrtetion in early post-partum dairy cattle. Domest. Anim. Endocrinol. 7:323-330, 1990.

DA ROSA, G.O.; WAGNER, W.C. Adrenal-gonad interactions in cattle. Corpus luteum function in intact and adrenalectomized heifers. J. anim. Sci. 52:10981105, 1981.

DAY, A.M.; MACMILLAN, K.L.; KILLEN, W.J.; BURKE, C.; MIRAMS, C.H. The use of a CIDR-B device with an oestrogen capsule in an artificial breeding programme with suckling beef cows. Proc. Aust. Assoc. Artif. Anim. Breed. Conf., 1992.

DeBOIS, C.H.W. Endometritis en vruchtbaarheid bij het rund. Tese, Utrecht, Holland, 145 p, 1961.

ELEY, D.S.; THATCHER, W.W.; HEAD, H.H.; COLLIER, R.J.; WILCOX, C.J.; CALL, E.P. Periparturient and postpartum endocrine changes of conceptus and maternal units in Jersey cows bred for milk yield. J. Dairy. Sc. 64:312-320, 1981.

FREDRIKSSON, G.; KINDHAL, H.; ALENIUS, S.; CARLSSON, U.; CORT, N.; EDQVIST, L.E.; UGGLA, A. Uterine infections and impaired reproductive performance mediated through prostaglandin release. 11th International Congress on Animal Reproduction and Artificial Insemination, 2629 June, Dublin. 5:81-90, 1988.
FREDRIKSSON, G.; KINDHAL, H.; SANDSTEDT, K.; EDQVIST, L.E. Intrauterine bacterial findings release of $\mathrm{PGF}_{2 \alpha}$ in the postpartum dairy cow. Zentralbl. Veterinaermed., Reihe A. 32:368-380, 1985.

GIER, H.T.; MARION, G.B. Uterus of the cow after parturition: involutional changes. American Journal of Veterinary Research 29(1):83-96, 1968.

GRUNERT, E. Disfunciones ovaricas. In: GRUNERT, E.; BERCHTOLD, M. Infertilidad en la vaca. Ed. Hemisferio Sur, Uruguay, $1^{a}$ ed., p. 133-176, 1988.

GRUNERT, E.; BIRGEL, E.H. Obstetrícia Veterinária. Ed. Sulina, Porto Alegre, 106-138, 1982.

HOPKINS, S.M. Bovine anestrus. In: MORROW, D.S. Current Therapy in Theriogenology 2: Diagnosis, treatment and prevention of reproductive diseases in small and large animals. W.B. Saunders, Toronto, p. 247-250, 1986.

JAINUDEEN, M.R.; HAFEZ, S.E. Gestação, fisiologia pré-natal e parto. In: HAFEZ, E.S.E. REPRODUÇÃ̃O ANIMAL, Ed. Manoele, $6^{\text {a }}$ ed., São Paulo. 217-240, 1995.

KINDAHL, H.; ODENSVIK, K.; AIUMLAMAI, S.; FREDRIKSSON, G. Utero-ovarian relationship during the bovine post partum period. Anim. Reprod. Sci. 28:363-369, 1992.

KOZICKI, L.E. Uber des postpartalen Zyklusverlauf bei Kuhen unter verschieden Haltungsbedingungen anhand von klinischen Erhebungen und von Progesteronbestimmungen in Milchproben mit Hilfe de Enzymimmuntests und Radioimmuntests. Tese de doutorado, Justus Liebig Universitat Giessen, Giessen, Alemanha, 186 p., 1982.

KOZICKI, L.E. Hormonio liberador de gonadotrofinas (GnRH): seus efeitos no puerpério tardio de vacas leiteiras. Pesq. agropec. bras. 26(4):505-509,1991.

KOZICKI, L.E.; YAMADA, M.L.A.; BOSCHETTI, C.C. Contribuição ao estudo da gonadorelina $(\mathrm{GnRH})$ sobre as características reprodutivas no puerpério precoce de bovinos leiteiros. Agrárias. 15(1):7-12, 1996.

LAMMING, G.E.; FOSTER, J.P.; BULMAN, D.C. Pharmacological control of reproduction cycles. Vet. Record. 104:156-160, 1979.

LINDELL, J.O.; KINDAHL, H. Exogenous prostaglandin $\mathrm{F}_{2 \alpha}$ promotes uterine involution in the cow. Acta Vet. Scand. 24:269-274, 1983.

LINDELL, J.O.; KINDAHL, H.; JANSSON, L.; EDQVIST, L.E. Post-partum release of prostaglandin $\mathrm{F}_{2 \alpha}$ and uterine involution in the cow. Theriogenology. 17:237-245, 1982.

LIPTRAP, R.M.; McNALLY, P.J. Steroid concentrations in cows with corticotropin-induced cystic ovarian follicles and the effect of prostaglandin $\mathrm{F}_{2 \alpha}$ and indomethacin given by intrauterine injection. Am. Vet. Res. 37:369-375, 1976.

MACMILLAN, K.L.; DAY, A.M. Treating the non-cycling cow. Proc. Ruakura Farm. Conf. 39:65-68, 1987.

MADEJ, A.; KINDAHL, H.; LARSSON, K.; EDQVIST, L.E. Sequential hormonal changes in the postpartum dairy cow. Acta Vet. Scand. 27:280-295, 1986.

MADEJ, A.; KINDAHL, H.; WOYNO, W.; EDQVIST, L. E.; STUPNICKI, R. Blood levels of 15-keto-13, 14-dihydroprostaglandin $\mathrm{F}_{2 \alpha}$ during the postpartum period in primiparous cows. Theriogenology. 21:279-287, 1984. 
MORROW, D.A. The role of nutrition in dairy cattle reproduction. In: MORROW, D.A. Current Therapy in Theriogenology: Diagnosis, treatment and prevetion of reproductive diseases in animals. W.B. Saunders, Toronto, p. 449-455, 1980.

MULVEHILL, P.; SREENAN, J. Improvement of fertility in post partum beef cows by treatment with PMSG and progestagen. J. Reprod. Fertil. 50:323-325, 1977.

MURPHY, M.G.; BOLAND, M.P.; ROCHE, J.F. The effect of a progesterone releasing intravaginal device on resumption of follicular activity and oestrus in autumn-calving Friesian dairy cows. In: DEKEL, N.A.; TSAFRIRI, A. Follicular development and the ovulatory response. Tiberias, Israel, p. 26, 1989.

MURPHY, M.G.; BOLAND, M.P.; ROCHE, J.F. Pattern of follicular growth and resumption of ovarian activity in pos-partum beef suckler cows. J. Reprod. Fertil. 90:523-533, 1990.

MURPHY, M.G.; ENRIGHT, W.J.; CROWE, M.A.; McCONELL, K.; SPINCER, L.J.; BOLAND, M.P.; ROCHE, J.F. Effects of dietary intake on pattern of growth of dominant follicles during the oestrus cycle in beef heifers. J. Reprod. Fertil. 92:333-338, 1991.

MYERS, T.R.; MYERS, D.; AGREGG, D.W.; MOSS, G.E. Endogenous opioid suppression of realease of luteining hormone during suckling in postpartum anestrus beef cows. Domest., Anim. Endocrinol. 6:183-190, 1989.

NETT, T.M. Function of the hypothalamic-hypophyseal axis during the post partum period in ewes and cows. J. Reprod. Fertil. 34 (suppl.):201-213, 1987.

OLSON, J.D.; BRETZLAFF, K.N.; MORTIMER, R.G.; BALL, L. The metritis-pyometra complex. In: MORROW, D.A. Current therapy in theriogenology 2. Saunders Co. Philadelphia, p. 227-236, 1986.

PRADO, R.; RHIND, S. M.; WRIGHT, A.; RUSSEL, A.J.F.; McMILLEN, S. R.; SMITH, A .J.; McNEILLY, A. S. Ovarian follicle populations, steroidogenicity and micromorphology at 5 and 9 weeks post partum in beef cows in two levels of body condition. Anim. Prod. 51:103-108, 1990.

RASBECH, N. Den normale involutio uteri hos koen. Veterinaermed. 2:655-687, 1950.

ROCHE, J.F. Synchronization of oestrus in cattle. World Rev. Anim. Prod. 12:79-88, 1976.
ROCHE, J.F. Synchronization of pregnancy rate in heifers and suckler cows after progesterone or prostaglandin treatments. Vet. Rec. 99:184-186, 1976.

ROCHE, J.F.; BOLAND, M.P. Turnover of dominant follicles in cattle of different reproductive states. Theriogenology. 35:81-90, 1991.

ROCHE, J.F.; CROWE, M.A.; BOLAND, M.P. Postpartum anoestrus in dairy and beef cows. Animal Reproduction Science. 28:371-378, 1992.

SCHALLENBERGER, E.; OERTERER, U.; HUTTERER, G. In: KARG, H.; SCHALLENBERGER, E. Factors influencing fertility in the post partum cow. Current topics in Veterinary Medicine and Animal Science, Martinus Nijhoff Publishers, The Hague. 20:123-146, 1982.

SCHALLENBERGER, E. Gonadotrophins and ovarian steroids in cattle. III. Pulsatile changes of gonadotrophin concentrations in the jugular vein post partum. Acta Endocrinol. 109:37-43, 1985.

SCHAMS, D. In: Breast feeding and the mother, CIBA Foundation Symposium. 45:27-48, 1976.

SHIRAR, A.; MARTINET, J. Postpartum ovarian activity and its interaction with the uterus in resuming cyclic activity post partum. In: KARG, H.; SCHALLENBERGER, E. Factors influencing fertility in the post partum cow. Current Topics in Veterinary Medicine and Animal Science, Martinus Nijhoff Publishers, The Hague. 20:67-94, 1982.

TERQUI, M.; CHUPIN, D.; GAUTHIER, D.; PEREZ, B.; PELOT, J.; MAULEON, P. In: KARG, H.; SCHALLERNBERGER, E. Factors influencing fertility in the post partum cow. Current Topics in Veterinary Medicine and Animal Science, Martinus Nijhoff Publishers, The Hague. 20:384-408, 1982.

THATCHER, W.W. In: PETERS, A.R.; LAMMING, G.E. Regulation of ovarian function in the post partum cow: an endocrine model. Vet. Record. 118:236-239, 1986.

WATSON, E.D. Plasma concentrations of PGFM in two cows with and in two cows without post partum emdometritis. Vet. Rec. 114:479-480, 1984.

WHITMORE, H.L. Early postpartum breeding. In: MORROW, D.A. Current Therapy in Theriogenology: Diagnosis, treatment and prevention of reproductive diseases in animals. W.B. Saunders, Toronto, p. 521-523, 1980. 